\title{
Assessing components of the natural inundation regime to restore through infrastructure projects
}

\author{
$\underline{\text { M. Montazeri }}{ }^{1}$, D. McCullough ${ }^{1}$, M.S. Gibbs ${ }^{1,2}$, M. Denny ${ }^{1}$ and K. Aldridge ${ }^{1}$ \\ ${ }^{1}$ Science, Monitoring and Knowledge Branch, Department of Environment, Water and Natural Resources, \\ Government of South Australia \\ ${ }^{2}$ School of Civil, Environmental and Mining Engineering, The University of Adelaide, South Australia
}

\begin{abstract}
Alteration to the natural flow regime of rivers and their floodplains has had a variety of impacts, including a reduction in habitat due to change infrequency and duration of inundation events and a corresponding reduction in abundance, distribution and condition of floodplain communities. Furthermore, aquatic habitats with hydraulic complexity, particularly those offering fast flowing habitat, have significantly declined under river regulation. The River Murray is an example where alterations to the flow regime associated with water extractions and regulation have resulted in degradation of ecological function and condition. With the implementation of the Basin Plan, overbank inundation events are expected to become more common compared to the recent past. However, under the Basin Plan the frequency and duration overbank events is still likely to remain lower than that of the natural water regime. Infrastructure projects and engineering solutions can be used to further restore a more natural inundation regime, extending the area of inundation for a given flow. For those biotic communities that are primarily driven by the duration and frequency of inundation events, this would be expected to increase their abundance, distribution or condition. As part of these infrastructure projects, the South Australian Riverland Floodplains Integrated Infrastructure Program (SARFIIP) has been initiated to improve the condition of the biotic communities of Pike Floodplain and Katarapko Floodplain, two important floodplain complexes of the River Murray in South Australia.
\end{abstract}

This paper presents the hydrological and hydraulic investigations undertaken as part of SARFIIP to assess inundation and hydraulic regimes of these two floodplains for a range of conditions:

- Without development; without modifications to the floodplains or development influences on flow in the River Murray,

- Baseline; current floodplain structures and the flow regime expected based on pre-Basin Plan conditions,

- Basin Plan; current floodplain structures with a range of Basin Plan water recovery scenarios considered,

- Intervention; proposed floodplain infrastructure of SARFIIP and Basin Plan water recovery scenarios considered.

The hydraulic modelling was done using MIKE FLOOD modelling platform and Inundation extents were modelled by simulating a range of flow rates for each Floodplains. The results indicated that the frequency of inundation of a given location on the floodplains was significantly reduced in the current and Basin Plan flow regimes compared to the natural flow regime. The ecological implications of this are that even under the Basin Plan, it is likely that native vegetation condition and extent will continue to decline resulting in the loss of habitat for fauna dependent on that habitat.

Comparison of inundation extents, frequencies and durations within the floodplain between natural conditions and Basin Plan conditions indicates that additional flows delivered to the Murray-Darling Basin through the Basin Plan alone cannot be expected to achieve full ecological benefits provided by natural conditions. Through the use of infrastructure solutions, the modelling suggests that inundation events can be created that align with the natural extent for the same frequency and duration of an events, particularly for longer duration events that are more difficult to restore through higher flows. This work has demonstrated the combined benefits of improving inundation regime through the Basin Plan, along with complimentary infrastructure projects.

Keywords: River Murray, South Australian Riverland Floodplains, infrastructure projects, hydraulic modelling, MIKE FLOOD 
Montazeri et al., Assessing components of the natural inundation regime to restore through infrastructure projects

\section{INTRODUCTION}

Alteration to the natural flow regimes is considered to be the most serious threat to ecological communities of rivers and their floodplains (Sparks, 1995; Ward et al, 1999). Alteration to the natural flow regimes can occur through changing the frequency, duration, magnitude and timing of flow events (Maheshwari et al, 1995; Poff et al, 1997; Boulton and Brock, 1999). Natural flow regimes are determined by the climate, run-off, catchment size and geomorphology without the impacts of dams, weirs, extraction and river management.

The flow regime of the River Murray has changed significantly over the years and has resulted in degradation of ecological function and condition (Gippel and Blackham, 2002). From the 1970s, the declining health of the River Murray became a serious concern. The development of various intergovernmental arrangements had not prevented the emergence of problems such as salinity, over-allocation of water resources and environmental degradation. The Basin Plan was adopted in 2012 to provide a more sustainable balance between the environmental, social and economic outcomes, and provide a framework to sustainably manage the water resources of the Murray-Darling Basin.

With the implementation of the Basin Plan, environmental flows will help to achieve the environmental objectives for water-dependent ecosystems described in the Basin Plan (MDBA, 2012c). However, where available flows remain unable to meet environmental water requirements, infrastructure projects and engineering solutions can be used to augment flows and may provide additional benefits. The South Australian Riverland Floodplains Integrated Infrastructure Program (SARFIIP) has been initiated in this regard to improve the flexibility of managing the system via new infrastructure and operational solutions.

The purpose of SARFIIP is to improve the ecological condition two important floodplain complexes of the River Murray in South Australia; Pike and Katarapko Floodplains (Figure 1). This will be achieved through the use of series of environmental regulators. Water entering the floodplain can be retained behind environmental regulators, enabling areas of floodplain at higher elevation to be flooded more often and for longer duration than would otherwise occur as a result of the prevailing flow regime. SARFIIP seeks to introduce variability in patterns of flooding and to mimic aspects of the natural water regime. The intent is to improve the condition of floodplain biotic communities.

A range of options have been investigated to restore some of the changes to inundation frequency and to achieve defined ecological objectives. Feasibility, cost effectiveness and ability to meet objectives have been considered in the analysis of all options.

This paper presents some existing investigations undertaken as part of SARFIIP to assess the impacts of increased water availability under the Basin Plan, and specifically to assess where infrastructure can be used to further enhance the improvements in inundation regime resulting from implementation

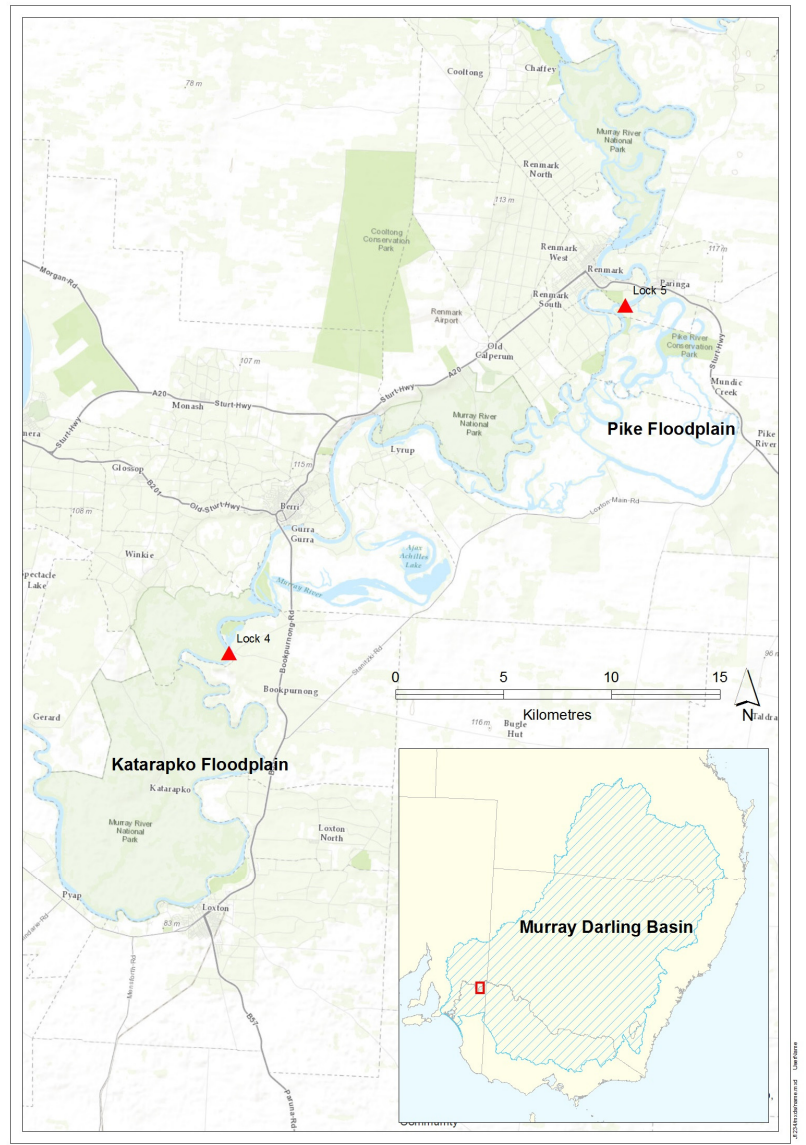

Figure 1. Pike and Katarapko Floodplains. of the Basin Plan. 
Montazeri et al., Assessing components of the natural inundation regime to restore through infrastructure projects

\section{METHODOLOGY}

\subsection{Hydraulic Modelling}

The numerical hydrodynamic models were originally produced and calibrated by Water Technology using the MIKE FLOOD modelling platform that combines the dynamic coupling of the one-dimensional MIKE 11 river model and MIKE 21 two dimensional model system (Water Technology, 2009). The MIKE FLOOD models were further refined and re-calibrated within the Science, Monitoring and Knowledge Branch of the Department of Environment, Water and Natural Resources (DEWNR) to address the updates implemented by the DEWNR (McCullough, 2013, McCullough, 2014).

To provide context on the potential benefits that could be restored through infrastructure, three key states of the floodplain were considered;

- Without development condition (All structures and locks were removed to create a model representing the floodplain as near to natural condition as possible)

- Baseline infrastructure condition (Existing condition)

- $\quad$ Proposed infrastructure condition (SARFIIP condition)

Inundation extents were modelled by simulating flood events with Average Recurrence Interval (ARI) of less than 10 years using MIKE FLOOD for each of the three key states of Pike and Katarapko Floodplains. The models assumed steady-state flow conditions, which means the water levels in the models were allowed sufficient time (5-6 days) to equalise under each ARI flood event.

\subsection{Flow indicators with their ecological benefits}

For the purpose of assessing the impacts of changed flow regimes, three flow thresholds were identified based on their ecological benefits. However, not all of the benefits described below would be expected to occur as a result of changes in inundation extent and duration alone. These flow thresholds were;

- Bankfull to riparian zone inundation - 35,000 ML/day threshold

Flows of 35,000 ML/day inundate only a small area of each of the floodplains, but provide an important role in the maintenance of floodplain anabranch riparian zones, and anabranch flowing habitat. A stable water level within the anabranches preserves a very narrow band of littoral zone vegetation, with potentially less species diversity than would occur with a variable water regime. Fluctuation between normal weir pool level and flows up to $35,000 \mathrm{ML} /$ day promotes a wider area of riparian habitat.

- Small to medium overbank floods - 60,000 ML/day threshold

Flows of 60,000 ML/day fill significant areas of the large meander basins and engage most areas mapped as supporting lignum shrublands at both Pike and Katarapko floodplains. The inundated, vegetated areas supply a dissolved and particulate organic matter load that will drive heterotrophic productivity. Over eight times the area of vegetated floodplain is inundated by a flood of $60,000 \mathrm{ML} /$ day, as compared with riparian zones at 35,000 ML/day. Bice et al (2014) state that flows of 60,000 ML/day in Spring and early Summer are likely to result in an increase in overall abundance, diversity and biomass of microbiota. Specialist temporary wetland micro and macroinvertebrate species will emerge from eggbanks, producing a diversity of species composition that is not observed with in-channel anabranch and river flows.

- $\quad$ Moderate to large overbank floods - 80,000 ML/day threshold

Floods of this magnitude inundate all retaining landscape basins and additionally cause widespread overbank flow out onto the shedding floodplain, which supports black box woodland and a diversity of 
Montazeri et al., Assessing components of the natural inundation regime to restore through infrastructure projects

shrublands. Black box woodland is important fauna habitat, particularly for hollow-nesting species (O'Malley and Sheldon, 1990). This magnitude of flood produces an inundation mosaic that brings woodland habitat into close proximity with aquatic habitat, in the higher elevation floodplain areas, to the benefit of floodplain fauna such as woodland birds, reptiles and bats. In a natural flood event, this scale of floodplain inundation creates widespread lateral connection with the main river with associated exchange of carbon and nutrients to fuel productivity, with the potential to provide ecological benefit in riverine and downstream wetland habitats (Bice et al, 2014). Large overbank floods provide breeding opportunities for continental and regionally nomadic water birds that prefer inundated woodland and lignum, providing the sufficient duration of flood (Rogers and Ralph, 2011).

\subsection{Frequency of inundation for different flow regime scenarios}

A number of Bain Plan water recovery scenarios were considered to assess the impact of different flow regimes on frequency of inundation within South Australia. These water recovery scenarios have been developed by the Murray-Darling Basin Authority (MDBA) to represent the changes in the flow regime that can be achieved through the recovery and use of water for the environment under the Basin Plan. The characteristics of the Basin Plan water recovery scenarios are discussed in detail in MDBA (2012a) and MDBA (2012b) for the relaxed constraint scenario.

All scenarios that were assessed in this investigation are as follows:

\section{- Without Development condition}

Floodplain conditions that are as near to natural conditions as possible and flow regime based on MDBA without development model run that excludes diversions and river infrastructure such as storages.

\section{- Baseline condition - Current flow regime}

Existing floodplain conditions with flow regime that is representative of 2009 conditions (pre Basin Plan river development) (MDBA, 2012a).

\section{- $\quad$ Baseline condition - BP2750}

Existing floodplain conditions with a flow regime based on a water recovery of $2750 \mathrm{GL}$. This is similar to the BP2800 scenario in MDBA (2012a).

\section{- Baseline condition - BP2400}

Existing floodplain conditions with a reduced water recovery of 2400 GL, representing a reduced water recovery volume.

\section{- Baseline condition - BP3200RC}

Existing floodplain conditions with an increased water recovery volume of $3200 \mathrm{GL}$ and relaxed flow delivery constraints within the Murray, representing an upper limit to the inundation regime expected from the Basin Plan (MDBA, 2012b).

Average Recurrence Interval (ARI) of flows that meet specific duration of inundation within the floodplain were identified for each scenario by applying statistical analysis on daily time series of calculated flow to South Australian (QSA) modelled by MDBA. The same season of a successful event used in MDBA (2012a) was adopted here, over the period between June 1 and December 31 each year. However, the analysis here has assumed the flow threshold must be met in one continuous event and no leniency is included for ordered events, which is different to the MDBA (2012a) approach. Three target durations of 30, 60 and 90 days were considered, which align with defined flow indicators. 
Montazeri et al., Assessing components of the natural inundation regime to restore through infrastructure projects

\section{DISCUSSION AND RESULTS}

\subsection{Impacts of increased water availability under the Basin Plan}

The hydraulic modelling results are described in Tables 1 to 3 . The hydraulic modelling shows that the frequency of flood events is significantly reduced for all modelled flow thresholds that contribute to floodplain inundation, compared with the Without Development scenario. The additional flows delivered by the Basin Plan scenarios provide an increase in inundation frequency, but the magnitude of these increases is much less than the overall deficit between Current conditions and the Without Development scenarios.

As presented in Tables 1 to 3, the increases in flow delivered by Basin Plan scenarios fail to reinstate flows that meet the environmental water preferences of a range of key species. Further, ecological communities in poor condition may require inundation at greater frequency than that required to maintain health, if long-term viability is to be restored. As such, it is unlikely that the improvements in flow under the Basin Plan alone can restore and maintain the ecosystems of the floodplains.

Table 1. Inundation frequency results for riparian zone flooding at 35,000 ML/day.

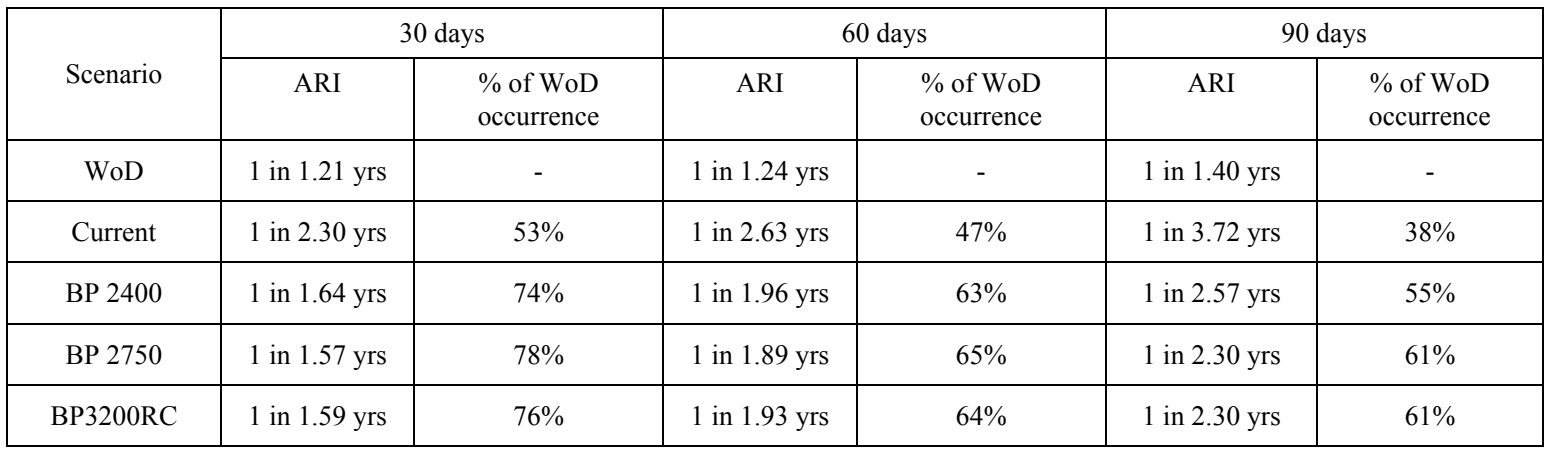

Table 2. Inundation frequency results for medium overbank floods - 60,000 ML/day.

\begin{tabular}{|c|c|c|c|c|c|c|}
\hline \multirow[b]{2}{*}{ Scenario } & \multicolumn{2}{|c|}{30 days } & \multicolumn{2}{|c|}{60 days } & \multicolumn{2}{|c|}{90 days } \\
\hline & ARI & $\begin{array}{l}\% \text { of } \mathrm{WoD} \\
\text { occurrence }\end{array}$ & ARI & $\begin{array}{l}\% \text { of WoD } \\
\text { occurrence }\end{array}$ & ARI & $\begin{array}{l}\% \text { of WoD } \\
\text { occurrence }\end{array}$ \\
\hline WoD & 1 in $1.84 \mathrm{yrs}$ & - & 1 in $2.24 \mathrm{yrs}$ & - & 1 in $2.94 \mathrm{yrs}$ & - \\
\hline Current & 1 in $4.68 \mathrm{yrs}$ & $39 \%$ & 1 in $7.36 \mathrm{yrs}$ & $30 \%$ & 1 in $17.17 \mathrm{yrs}$ & $17 \%$ \\
\hline BP 2400 & 1 in $3.81 \mathrm{yrs}$ & $48 \%$ & 1 in $4.68 \mathrm{yrs}$ & $48 \%$ & 1 in $10.30 \mathrm{yrs}$ & $29 \%$ \\
\hline BP 2750 & 1 in $3.43 \mathrm{yrs}$ & $54 \%$ & 1 in 5.15 yrs & $43 \%$ & 1 in 9.36 yrs & $31 \%$ \\
\hline BP3200RC & $1 \mathrm{in} 3.22 \mathrm{yrs}$ & $57 \%$ & $1 \mathrm{in} 4.12 \mathrm{yrs}$ & $54 \%$ & 1 in $7.92 \mathrm{yrs}$ & $37 \%$ \\
\hline
\end{tabular}

Table 3. Inundation frequency results for large overbank floods - 80,000 ML/day.

\begin{tabular}{|c|c|c|c|c|c|c|}
\hline \multirow{2}{*}{ Scenario } & \multicolumn{2}{|c|}{30 days } & \multicolumn{2}{|c|}{60 days } & \multicolumn{2}{|c|}{90 days } \\
\hline & ARI & $\begin{array}{l}\% \text { of WoD } \\
\text { occurrence }\end{array}$ & ARI & $\begin{array}{l}\% \text { of WoD } \\
\text { occurrence }\end{array}$ & ARI & $\begin{array}{l}\% \text { of WoD } \\
\text { occurrence }\end{array}$ \\
\hline WoD & 1 in $2.83 \mathrm{yrs}$ & - & 1 in $4.95 \mathrm{yrs}$ & - & 1 in $12.38 \mathrm{yrs}$ & - \\
\hline Current & 1 in $9.00 \mathrm{yrs}$ & $31 \%$ & 1 in $14.14 \mathrm{yrs}$ & $35 \%$ & 1 in $24.75 \mathrm{yrs}$ & $50 \%$ \\
\hline BP 2400 & 1 in 7.62 yrs & $37 \%$ & $1 \mathrm{in} 16.50 \mathrm{yrs}$ & $30 \%$ & $1 \mathrm{in} 33.00 \mathrm{yrs}$ & $38 \%$ \\
\hline BP 2750 & $1 \mathrm{in} 7.07 \mathrm{yrs}$ & $40 \%$ & 1 in $14.14 \mathrm{yrs}$ & $35 \%$ & 1 in $19.80 \mathrm{yrs}$ & $63 \%$ \\
\hline BP3200RC & 1 in $8.25 \mathrm{yrs}$ & $34 \%$ & 1 in 14.14 yrs & $35 \%$ & 1 in $33.00 \mathrm{yrs}$ & $38 \%$ \\
\hline
\end{tabular}


Montazeri et al., Assessing components of the natural inundation regime to restore through infrastructure projects

\subsection{Restoring natural inundation regime through infrastructure}

In order to deliver more environmental benefits beyond those that are expected to be achieved under the Basin Plan through increased flow alone, engineering solutions can be incorporated. As an example, Figure 2 presents the inundation extent corresponding to different flow regimes for a 1 in 3 year event with a 90 day duration for the Katarapko floodplain. Overlayed with this in the hatched area is the inundation extent that can be managed using SARFIIP infrastructure. As shown by the light blue colour, under natural conditions it was estimated that once every three years Katarapko Floodplain was inundated for at least 90 days by flow of around $60000 \mathrm{ML} /$ day, whereas under current conditions (dark blue) a flow of around $30 \quad 000 \mathrm{ML} / \mathrm{d}$ represents a similar flow event frequency and duration, resulting in a smaller estimated portion to be inundated.

With the implementation of the Basin Plan, an increase in the area meeting the example regime can be seen (yellow), however there is still a gap between the environmental outcomes the Basin Plan can provide and what would be expected from a natural wetting regime. SARFIIP proposed solutions can be used to further restore the inundation regime.

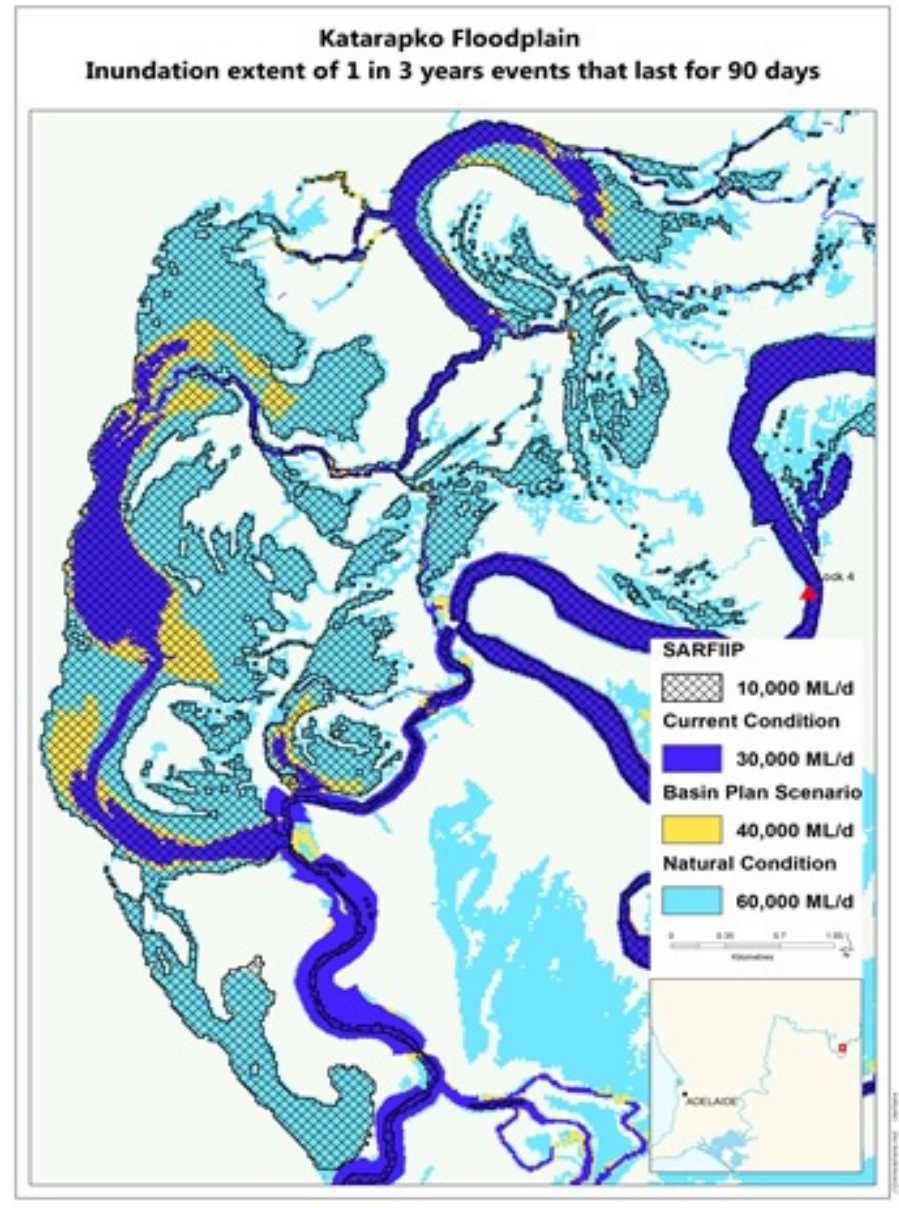

Figure 2. Katarapko Floodplain Inundation extent of 1 in 3 years events that last for 90 days.

\section{CONCLUSIONS}

Environmental flows through the implementation of the Basin Plan will help to achieve the environmental objectives for water-dependent ecosystems described in the Basin Plan. However, where available flows remain unable to meet environmental water requirements. This work has demonstrated the combined benefits of improving inundation regime through the Basin Plan, along with complimentary infrastructure projects. Whilst this is likely to provide benefits to those biotic communities that are primarily driven by the duration and frequency of inundation events, further consideration of impacts upon those species and ecological processes that are dependent upon changes in hydrological conditions is required for planning infrastructure design and operations.

\section{ACKNOWLEDGMENTS}

The authors would like to thank Volmer Berens and Brad Hollis, staff of the Department of Environment, Water and Natural Resources of South Australia for their constructive comments in the preparation of this paper. 
Montazeri et al., Assessing components of the natural inundation regime to restore through infrastructure projects

\section{REFERENCES}

Boulton, A.J. and Brock, M.A. 1999. Australian Freshwater Ecology: Processes and Management. Glen Eagles Publishing, Adelaide.

Bice CM, Zampatti BP, Aldridge KA, Furst D, Kilsby N, Maxwell S, Nicol J, Oliver R, Rogers D, Turner R \& Wallace $\mathrm{T}$ (2014). An assessment of the knowledge requirements to support effective provisions of environmental water in the South Australian Murray-Darling Basin: Part 2 - Development of hydro-ecological conceptual models and identification of knowledge gaps in current understanding of flow-biota relationship. Prepared by the South Australian Research and Development Institute (Aquatic Sciences) for the Goyder Institute for Water Research. Goyder Institute for Water Research Technical Report Series No. 14/18, Adelaide, South Australia. ISSN: 18392725

Gippel, C.J. and Blackham, D. 2002. Review of environmental impacts of flow regulation and other water resource developments in the River Murray and Lower Darling River system. Final Report by Fluvial Systems Pty Ltd, Stockton, to Murray-Darling Basin Commission, Canberra, ACT.

O'Malley, C. \& Sheldon, F. \& Nature Conservation Society of South Australia (1990). Chowilla floodplain biological study. Nature Conservation Society of South Australia, Adelaide.

MDBA, 2012a, Hydrologic modelling to inform the proposed Basin Plan - methods and results, MDBA publication no: 17/12, Murray-Darling Basin Authority, Canberra.

MDBA, 2012b, Hydrologic modelling of the relaxation of operational constraints in the southern connected system: Methods and results, MDBA publication no: 76/12, Murray-Darling Basin Authority, Canberra.

MDBA, 2014, Development of the benchmark model for calculation of supply contributions, MDBA Publication no: 25/13, Preliminary Draft, Murray-Darling Basin Authority, Canberra.

Maheshwari, B.L., Walker, K.F. and McMahon, T.A. 1995. Effects of river regulation on the flow regime of the River Murray, Australia. Regulated Rivers: Research and Management 10: 15-38

McCullough DP, 2013, Riverine Recovery Pike Floodplain Hydraulic Modelling 2012-13, DEWNR Technical Note, Government of South Australia, through Department of Environment, Water and Natural Resources, Berri

McCullough, D. P., 2014, Riverine Recovery Katfish Reach Hydraulic Modelling 2012-13, Riverine Recovery Project Technical Note, Government of South Australia, through Department of Environment, Water and Natural Resources, Berri.

Poff, N.L., Allan, J.D., Bain, M.B., Karr. J.R. Prestegaard, K.L., Richter, B.D., Sparks, R.E. and Stromberg, J.C. 1997. The natural flow regime: A paradigm for river conservation and restoration.BioScience. 47: 769-784.

Rogers K \& Ralph TJ (2011) Floodplain wetland biota in the Murray-Darling basin: water and habitat requirements, CSIRO publishing, Collingwood, Victoria, Australia.

Sparks, R.E. 1995. Need for ecosystem management of large rivers and floodplains. BioScience 45:168-182.

Ward, J.V., K. Tockner, and F. Schiemer. 1999. Biodiversity of floodplain ecosystems: ecotones and connectivity. Regulated Rivers: Research and Management 15:125-139.

Water Technology, 2009, Pike River Project Hydraulic Model Development, Water Technology, September 2009, Reference No. J1149_D01, report for SA MDB NRM Board. 